\title{
2021 Henry Clifton Sorby Award
}

ㄷ) ASM International 2021

Professor C. Barry Carter, of the University of Connecticut, is the recipient of the 2021 Sorby Award. The International Metallographic Society presents the Henry Clifton Sorby Award annually to an internationally recognized figure for lifetime achievement in the fields of metallography and materials science. Recipients are acknowledged for their contributions and dedication to research, teaching, and/or laboratory sales and service. This is the highest honor presented by the International Metallographic Society.

Prof. Carter is professor of Materials Science and Engineering at the University of Connecticut in Storrs, Connecticut. He is also CINT Distinguished Affiliate Scientist at Sandia National Laboratories, visiting professor at the University of Manchester, and serves as editor-in-chief of the Journal of Materials Science. Prof. Carter earned a Sc.D. from Cambridge University, U.K. in 2005 and a D. Phil. from Oxford University in 1976. His key area of expertise is the microscopy of ceramics, semiconductors, and metals, especially using transmission electron microscopy.

With more than 20 awards and honors, Prof. Carter's accomplishments have been recognized around the globe. His awards include Honorary Fellow of the Royal Microscopical Society, Honorary Member of the Indian Institute of Metals, Das Gupta Memorial Lecturer (Electron Microscope Society of India), Distinguished Physical Scientist (Microscopy Society of America), Alexander von Humboldt Senior Award, and John Simon Guggenheim Fellow Award. He has more than 310 journal publications and 400 conference papers to his credit. Two textbooks that he authored are in the top three of Springer's most downloaded in chemistry/materials of all time.

Prof. Carter's research and academic accomplishments are complemented by his leadership skills, having served as president of both the International Federation of Societies of Microscopy (2011-2014) and the Microscopy Society of America (1997). He feels that the driving force in his career has been to combine the highest standards of scientific research with a commitment to education and service to the scientific community, especially using electron microscopy and AFM.

The lecture, entitled "Microscopy, Dislocations and Interfaces," will be held at IMAT 2021 in September in St. Louis, Missouri.

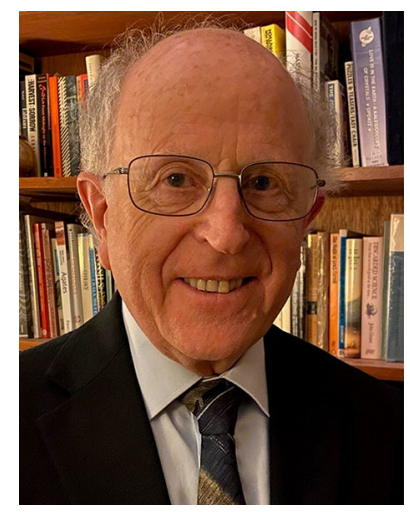

Professor C. Barry Carter

An abstract of the lecture is presented here.

\section{Microscopy, Dislocations and Interfaces}

This talk will combine three topics that have occupied the speaker for the past 50 years. TEM is the essential tool for fully characterizing, and thereby understanding, dislocations and interfaces in all materials, not only crystalline materials, but it is essential to combine TEM with other imaging techniques and with spectroscopy, particularly using X-rays generated and energy lost as the electrons interact with the specimen, to obtain a full picture. It is interesting to examine how early approaches to Materials Science have helped or hindered our understanding of imperfections in ceramics, metals and semiconductors. The talk will be illustrated by images of unusual defects in different materials and plans to conclude with suggestions of topics that should be revisited now that the tools and techniques for doing so can actually answer some of our earliest questions, keeping in mind why those were our earliest questions.

Publisher's Note Springer Nature remains neutral with regard to jurisdictional claims in published maps and institutional affiliations. 